$\xi=1$ 圆

\title{
Attachment Insecurities and Marital Satisfaction
}

\author{
Fatahyah Yahya $^{1 *}$, Nurhanani Md Husaini ${ }^{2}$, Aina Razlin Mohammad Roose ${ }^{3}$, Nur Fatihah Mat Yusoff ${ }^{4}$ \\ ${ }^{1}$ Universiti Malaysia Sarawak \\ ${ }^{2}$ Universiti Malaysia Sarawak \\ ${ }^{3}$ Universiti Malaysia Sarawak \\ 4Universiti Malaysia Sarawak \\ *Corresponding author E-mail: yfatahyah@unimas.my
}

\begin{abstract}
This study identifies the relationship between attachment insecurities; Attachment Avoidance and Attachment Anxiety, and Marital Satisfaction; Dyadic Cohesion, Dyadic Satisfaction, Dyadic Consensus, and Dyadic Affectional Expression among married couples. A correlational research design was adopted in this study to address the objectives of the research. Seventy respondents among married couples in West Peninsular of Malaysia were selected to participate in this research. Two sets of questionnaires were developed and reviewed by two expert panels before piloting and distributing to the participants. The structure and content of the questionnaires were specific to main two areas; Experience in Close Relationship (ECR) and Dyadic Adjustment Scale (DAS). The data was collected and analysed using SPSS descriptive statistic and Pearson correlation. The findings indicated that there was a significant relationship between attachment insecurities and marital satisfaction. Furthermore, it is recommended based on the results that community counsellors' conduct group counselling sessions to facilitate married couples' understanding of attachment insecurities which will help to enhance the satisfaction in their marital relationships. It is also recommended based on the work performed, limitations and findings in this study that further research is conducted to conduct a similar research program, with a broader and more substantial population size covering multiple communities, again with a specific focus on married couples and to improve their marital satisfaction with their relationships.
\end{abstract}

Keywords: Attachment Avoidance; Attachment Anxiety; Attachment Insecurities; Marital Satisfaction

\section{Introduction}

Attachment theory can be defined as a psychological, evolutionary, and ethological theory regarding relationships between individuals. The most important element, for example, is in the case of a young child needing to develop a relationship with at least one primary caregiver for social and emotional development to occur normally (1). Attachment insecurities are categorised into two distinct types; attachment avoidant and attachment anxiety. Attachment avoidant means that adults desire a high level of independence, often appearing to avoid attachment between theselves but instead, view themselves as self-sufficient and invulnerable to the feeling of attachment and not requiring a close relationship. Whereas, attachment anxiety means that adults seek high levels of intimacy, approval and responsiveness from their partners, often becoming overly dependent, and tending to be less trusting with fewer positive views about themselves and their partners. Moreover, this may exhibit high levels of independence, often resulting in worry and impulsiveness within their relationship (2).

Limited research is available on attachment insecurities and marital satisfaction in Malaysia, however, previous research has been undertaken on "Dyadic Consensus and Satisfaction among Married and Dating Couples in Malaysia" (3). According to Cai-Lian et al. (3), most research on relationships in recent years has focussed only on the quality of relationships of couples and that married, and dating couples tend to rate the quality of their relationship much differently. The study by Cai-Lian (3) to explore the findings of (3) in addition to examining the role of the gender and the couple's satisfaction and consensus. A survey of 160 participants, as a representative population sample, comprising of 80 married individuals, and 80 non-married individuals but who were presently dating participated in the survey. The results of the study demonstrated that from several hypotheses formulated for the study, the second hypothesis was accepted, predicting that there were significant differences found between the married couples and the dating couples regarding dyadic satisfaction. Indeed, based on the research it was determined that there were further differences found in the population sample for dating.

Research has also been carried out on "Dimensionality of the Chinese Dyadic Adjustment Scale" based on Confirmatory Factor Analyses (4). According to Daniel \& Shek (4) the responses of 1,501 Chinese married adults based on the Chinese version of the Dyadic Adjustment Scale (C-DAS), the confirmatory factor analyses showed that there were four primary factors abstracted from the C-DAS (Dyadic Consensus, Dyadic Cohesion, Dyadic Satisfaction and Affectional Expression) that were subsumed under a second-order Dyadic Adjustment factor. The findings showed that the second-order factor, which is a dyadic adjustment, was able to accommodate the four primary factors and the loading of the four primary factors on the second order factor. Notably, Daniel considered this finding acceptable. In a separate research study, entitled "Eye of the Beholder: The Individual and Dyadic Contributions of Empathic Accuracy and Perceived Emphatic Effort to Relationship Satisfaction" (5), the focus was on the confirmatory of the Chinese version of the Dyadic Adjustment Scale. The research was carried out in China, given the cultural differences compared to Malaysia. The study examined the links between two distinct facets of empathy; empathic accuracy and perceived em- 